Research Article

\title{
Correlation of Serum Cardiac Markers with Acute Decompensating Events in Liver Cirrhosis
}

\author{
Miaomiao Li, ${ }^{1,2}$ Zeqi Guo,, ${ }^{1}$ Dan Zhang, ${ }^{3}$ Xiangbo Xu, ${ }^{1,4}$ Fernando Gomes Romeiro, ${ }^{5}$ \\ Andrea Mancuso, ${ }^{6}$ Jingqiao Zhang, ${ }^{1,4}$ Ruirui Feng, ${ }^{1}$ Xinmiao Zhou, ${ }^{1}$ Cen Hong, \\ and Xingshun Qi $\mathbb{D}^{1}$ \\ ${ }^{1}$ Liver Cirrhosis Group, Department of Gastroenterology, General Hospital of Northern Theater Command (Formerly General \\ Hospital of Shenyang Military Area), Shenyang, China \\ ${ }^{2}$ Department of Clinical Laboratory, The First Hospital of Lanzhou University, Lanzhou, China \\ ${ }^{3}$ Department of General Surgery, General Hospital of Northern Theater Command (Formerly General Hospital of Shenyang \\ Military Area), Shenyang, China \\ ${ }^{4}$ Department of Pharmaceutical Sciences, Shenyang Pharmaceutical University, Shenyang, China \\ ${ }^{5}$ Faculdade de Medicina de Botucatu UNESP, Campus de Botucatu, S/N, Botucatu, SP, Brazil \\ ${ }^{6}$ Department of Internal Medicine, ARNAS Civico, Palermo, Italy \\ Correspondence should be addressed to Xingshun Qi; xingshunqi@126.com
}

Received 7 May 2020; Revised 1 September 2020; Accepted 14 September 2020; Published 24 September 2020

Academic Editor: Niccola Funel

Copyright (c) 2020 Miaomiao Li et al. This is an open access article distributed under the Creative Commons Attribution License, which permits unrestricted use, distribution, and reproduction in any medium, provided the original work is properly cited.

\begin{abstract}
Background and Aim. Liver cirrhosis is often accompanied by insidious cardiac dysfunction. This retrospective cross-sectional study is aimed at exploring the correlation between serum cardiac markers and decompensating events in liver cirrhosis. Methods. Cirrhotic patients who were consecutively hospitalized between January 2016 and March 2019 were screened. Serum cardiac biomarkers at admission, including N-Terminal pro-B-type natriuretic peptide (NT-pro BNP), high-sensitivity cardiac troponin $\mathrm{T}$ (hs-cTnT), creatine kinase (CK), creatine kinase MB (CK-MB), and lactate dehydrogenase (LDH), were collected. Acute decompensating events at admission, primarily including ascites, acute gastrointestinal hemorrhage, and acute-on-chronic liver failure (ACLF), were recorded. Results. The NT-pro BNP level was significantly higher in cirrhotic patients with acute decompensating events than in those without any decompensating events (median: $140.75 \mathrm{pg} / \mathrm{mL}$ versus $41.86 \mathrm{pg} / \mathrm{mL}, P<0.001$ ). The NT-pro BNP level significantly correlated with ascites, acute gastrointestinal hemorrhage, and ACLF. The hs-cTnT level was significantly higher in cirrhotic patients with acute decompensating events than in those without decompensating events (median: $0.008 \mathrm{ng} / \mathrm{mL}$ versus $0.006 \mathrm{ng} / \mathrm{mL}, P=0.007)$. The hs-cTnT level significantly correlated with acute gastrointestinal hemorrhage, but not ascites or ACLF. $\mathrm{LDH}$ (185.0 U/L versus $173.5 \mathrm{U} / \mathrm{L}, P=0.281)$, CK (71 U/L versus $84 \mathrm{U} / \mathrm{L}, P=0.157)$, and CK-MB (29.5 U/L versus $33.0 \mathrm{U} / \mathrm{L}, P=0.604$ ) levels were not significantly different between cirrhotic patients with and without acute decompensating events. Conclusion. The elevated NT-pro BNP level seems to be closely related to the development of acute decompensating events in liver cirrhosis.
\end{abstract}

\section{Introduction}

Liver cirrhosis is a state of systemic hyperdynamic circulation characterized by increased cardiac output and decreased peripheral resistance, especially in the presence of decompensating events [1]. This disease activates the sympathetic nervous system (SNS) and the renin-angiotensin-aldosterone system (RAAS), which further increases the myocardial tension and ultimately results in chronic cardiac dysfunction [2-4]. Consequently, the levels of atrial natriuretic peptide (ANP), brain natriuretic peptide (BNP), and troponin I (TnI) are increased [5]. Such chronic cardiac dysfunction in liver cirrhosis presenting with systolic dysfunction, diastolic dysfunction, and electrophysiological changes is known as "cirrhotic cardiomyopathy" [4]. An interaction between liver cirrhosis and cardiac dysfunction suggests that serum cardiac 
markers may be valuable in evaluating the disease state of liver cirrhosis.

BNP and N-Terminal pro-B-type natriuretic peptide (NT-pro BNP) are secreted in response to increased myocardial stress [6-8]. The NT-pro BNP level is significantly increased in liver cirrhosis, which may be related to cardiac dysfunction [9-11]. Also, the NT-pro BNP level significantly correlates with the severity of liver dysfunction and prognosis of cirrhotic patients $[7,12]$. On the other hand, highsensitivity cardiac troponin $\mathrm{T}$ (hs-cTnT), another highly specific and sensitive marker of myocardial injury, is also significantly increased in patients with liver cirrhosis. Thus, NTpro BNP as well as hs-cTnT may be valuable for prognostic assessment of liver cirrhosis [12]. However, their correlation with acute decompensating events in liver cirrhosis has never been explored yet. Additionally, the clinical significance of other biomarkers of cardiac injury, such as creatine kinase $(\mathrm{CK})$, creatine kinase $\mathrm{MB}(\mathrm{CK}-\mathrm{MB})$, and lactate dehydrogenase (LDH), in liver cirrhosis remains unclear.

Therefore, this study is aimed at exploring the relationship between these cardiac markers and decompensating events in cirrhosis.

\section{Methods}

2.1. Patients. We have prospectively collected the demographic, clinical, and laboratory data of cirrhotic patients who were consecutively admitted to the Department of Gastroenterology of the General Hospital of Northern Theater Command (formerly General Hospital of Shenyang Military Area) and treated by an attending physician (XQ) since January 1, 2016. Until March 31, 2019, there were a total of 761 admissions. We retrospectively screened the patients who had undergone the evaluation of laboratory data regarding serum cardiac markers during the hospitalizations. Exclusion criteria were as follows: (1) confirmed or suspected diagnosis of malignancy, (2) severe renal insufficiency (estimated glomerular filtration rate $(\mathrm{eGFR})<30 \mathrm{~mL} / \mathrm{min} / 1.73 \mathrm{~m}^{2}$ ), (3) cardiac diseases (i.e., heart failure, coronary atherosclerotic heart disease, and atrial fibrillation), (4) ischemic stroke, and (5) absence of data regarding serum cardiac markers detected during the hospitalizations. Repeated admissions of the same patient were not deliberately excluded, because this study focused on the in-hospital outcome and decompensating events during the hospitalizations, but not on long-term follow-up outcomes. If a patient had multiple measurements of serum cardiac markers during the same hospitalization, we selected the data obtained at the first time of blood collection. The study protocol was approved by the Medical Ethics Committee of our hospital. We primarily collected demographic data, etiology of liver cirrhosis, decompensating events at admissions, and laboratory tests including serum cardiac markers.

2.2. Definitions and Diagnosis. Acute gastrointestinal hemorrhage was defined as previously described [13, 14]. The Child-Pugh score was calculated [15]. Model for end-stage liver disease (MELD) and MELD with sodium (MELD-Na) scores were calculated according to an equation updated by the OPTN/UNOS (American Organ Acquisition and Transplantation Network/Organ Resource Sharing Network) in 2016 [16], as follows:

$$
\begin{aligned}
\operatorname{MELD}(i)= & 9.57 \times \ln (\text { creatinine } \mathrm{mg} / \mathrm{dL})+3.78 \\
& \times \ln (\text { bilirubin } \mathrm{mg} / \mathrm{dL})+11.2 \\
& \times \ln (\mathrm{INR})+6.43, \\
M E L D-N a= & M E L D(i)+1.32 \times(137-\mathrm{Na}) \\
& -[0.033 \times M E L D(i) \times(137-\mathrm{Na}) .
\end{aligned}
$$

If $\mathrm{Na}^{+}<125 \mathrm{mmol} / \mathrm{L}$, it is set to 125 ; if $\mathrm{Na}^{+}>137$, it is set to 137 .

The grade of ascites was defined according to the consensus of the International Ascites Club [17]. Patients with acute-on-chronic liver failure (ACLF) were identified by the recommendations of the Asian Pacific Association for the Study of the Liver (APASL) consensus [18, 19]. Severe renal insufficiency was defined as eGFR $<30 \mathrm{~mL} / \mathrm{min} / 1.73 \mathrm{~m}^{2}$ [20]. The eGFR was calculated using the simplified equation [21], as follows:

$$
\begin{aligned}
e \mathrm{GFR}\left(\mathrm{mL} / \mathrm{min} \text { per } 1.73 \mathrm{~m}^{2}\right) \\
=186.3 \times \text { serum creatinine } \\
\quad \text { concentration }(\mathrm{mg} / \mathrm{dL})(\exp [-1.154]) \\
\quad \times \text { age }(\exp [-0.203]) \times(0.742 \text { if } \text { female }) \\
\quad \times(1.212 \text { if black })
\end{aligned}
$$

2.3. Groups. We divided cirrhotic patients into 5 groups: (1) cirrhotic patients without acute decompensating events, (2) cirrhotic patients with acute decompensating events, (3) cirrhotic patients with ascites, (4) cirrhotic patients with acute gastrointestinal hemorrhage, and (5) cirrhotic patients with ACLF.

2.4. Measurement of Serum Cardiac Markers. All serum cardiac markers were measured at the Department of Laboratory of our hospital. They included NT-pro BNP detected by enzyme-linked immunosorbent assay (ELISA) (double antibody sandwich method) with a normal range of 0 $125 \mathrm{pg} / \mathrm{mL}$, hs-cTnT by ELISA (double antibody sandwich method) with a normal range of $0-0.05 \mathrm{ng} / \mathrm{mL}$, CK by coupled-enzyme assay with a normal range of 38-174 U/L, CK-MB by immune inhibition assay with a normal range of 0-24 U/L, LDH by the spectrophotometric method with a normal range of 109-245 U/L, and hs-CRP by latex immune turbidimetry with a normal range of $0-3 \mathrm{mg} / \mathrm{L}$. Only the data obtained at the first time of measurement were selected, thus avoiding the influence of drugs used during hospitalization.

2.5. Statistical Analyses. Continuous data were expressed as mean \pm standard deviation and median (quartiles) and were compared by using the Wilcoxon rank-sum test. Categorical data were expressed as frequency (percentage) and were compared by using the chi-square test. Considering that age and gender are important factors influencing serum NT- 


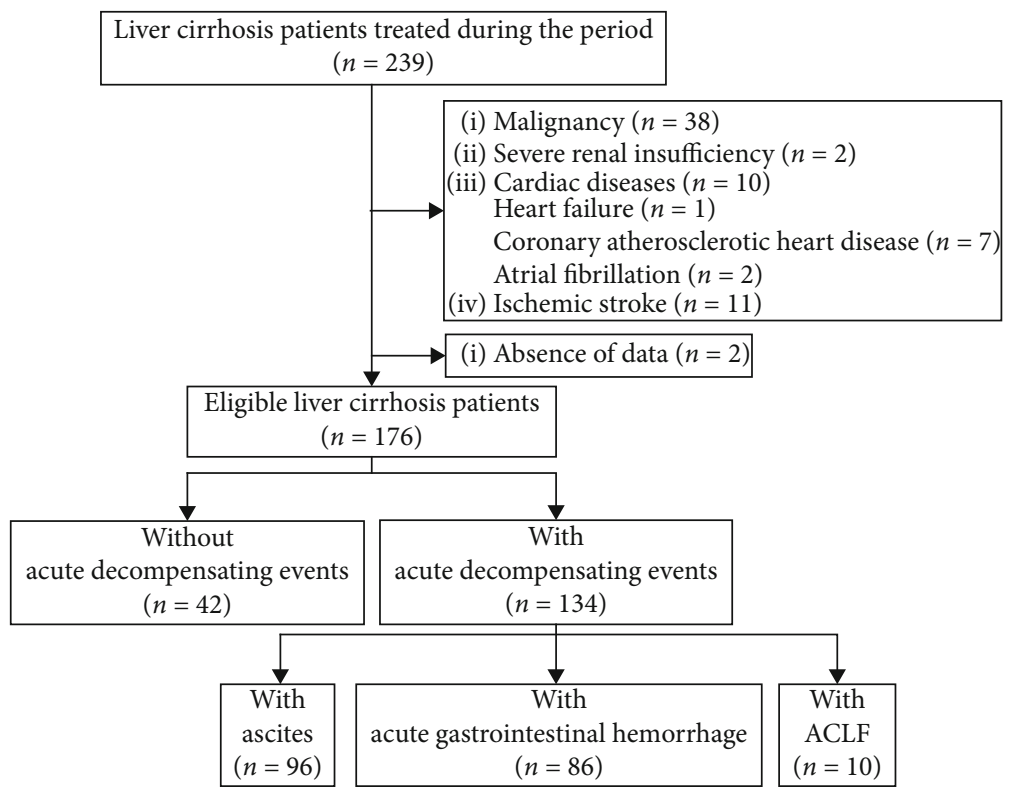

Figure 1: A flow chart of patient selection.

pro BNP and hs-cTnT levels [22-26], partial correlation analysis was adjusted for age and gender to analyze the correlation of serum NT-pro BNP and hs-cTnT with liver disease conditions. Pearson or Spearman tests were performed to analyze the correlation between disease conditions and other serological cardiac markers, such as CK, CK-MB, and LDH. Multivariate linear regression analysis was performed to analyze the correlation of serological cardiac markers with categorical variables. A two-sided $P<0.05$ was considered to be statistically significant. SPSS statistics software version R23.0.0.0 was employed to perform all statistical analyses.

\section{Results}

3.1. Patients. Overall, 176 patients with liver cirrhosis were included (Figure 1), of whom $42(23.86 \%)$ did not have any decompensating events but conducted regular follow-up and/or prophylactic endoscopic variceal treatment and 134 (76.14\%) had acute decompensating events, including ascites ( $n=96,71.64 \%)$, acute gastrointestinal hemorrhage $(n=86$, $64.18 \%)$, and $\operatorname{ACLF}(n=10,7.46 \%)$.

3.2. Comparison between Cirrhotic Patients with and without Decompensating Events. Cirrhotic patients with decompensating events had significantly higher levels of NT-pro BNP $(P<0.001)$ and hs-cTnT $(P=0.007)$ than those without decompensating events (Figure 2), but the differences in the levels of CK, CK-MB, and LDH were not significant between them (Table 1).

Cirrhotic patients with ascites had significantly higher levels of NT-pro BNP $(P<0.001)$ and hs-cTnT $(P=0.002)$ than those without decompensating events (Figure 2), but the differences in the levels of CK, CK-MB, and $\mathrm{LDH}$ were not significant between them (Table 2).

Cirrhotic patients with acute gastrointestinal hemorrhage had significantly higher levels of NT-pro BNP $(P<0.001)$ and hs-cTnT $(P=0.003)$ than those without decompensating events (Figure 2), but the differences in the levels of CK, CK$\mathrm{MB}$, and $\mathrm{LDH}$ were not significant between them (Table 2).

Cirrhotic patients with ACLF had a significantly higher level of NT-pro BNP $(P<0.001)$ than those without decompensating events (Figure 2), but the differences in the levels of $\mathrm{CK}, \mathrm{CK}-\mathrm{MB}$, and $\mathrm{LDH}$ were not significant between them (Table 2).

3.3. Correlation of Serum Cardiac Markers with Child-Pugh and MELD Scores in Patients with Liver Cirrhosis. Partial correlation analyses demonstrated that the NT-pro BNP level significantly correlated with Child-Pugh and MELD scores. These correlations were observed in all the cirrhotic patients and in those with decompensating events, but not in those without decompensating events (Table 3). Partial correlation analyses demonstrated that the hs-cTnT level had no significant correlation with Child-Pugh and MELD scores in cirrhotic patients regardless of the presence of decompensating events (Supplementary Table 1). Correlation analyses demonstrated that CK (Supplementary Table 2) and CK-MB (Supplementary Table 3) levels did not significantly correlate with Child-Pugh and MELD scores in cirrhotic patients. On the other hand, the LDH level significantly correlated with Child-Pugh and MELD scores in cirrhotic patients (Supplementary Table 4).

3.4. Correlation between Serum Cardiac Markers and Decompensating Events in Cirrhotic Patients. Age- or gender-adjusted multivariate linear regression analyses demonstrated that the NT-pro BNP level significantly correlated with overall acute decompensating events, ascites, acute gastrointestinal hemorrhage, and ACLF (Table 4); the hs-cTnT level significantly correlated with overall acute decompensating events and acute gastrointestinal hemorrhage, but not ascites or ACLF (Supplementary Table 5); CK and 


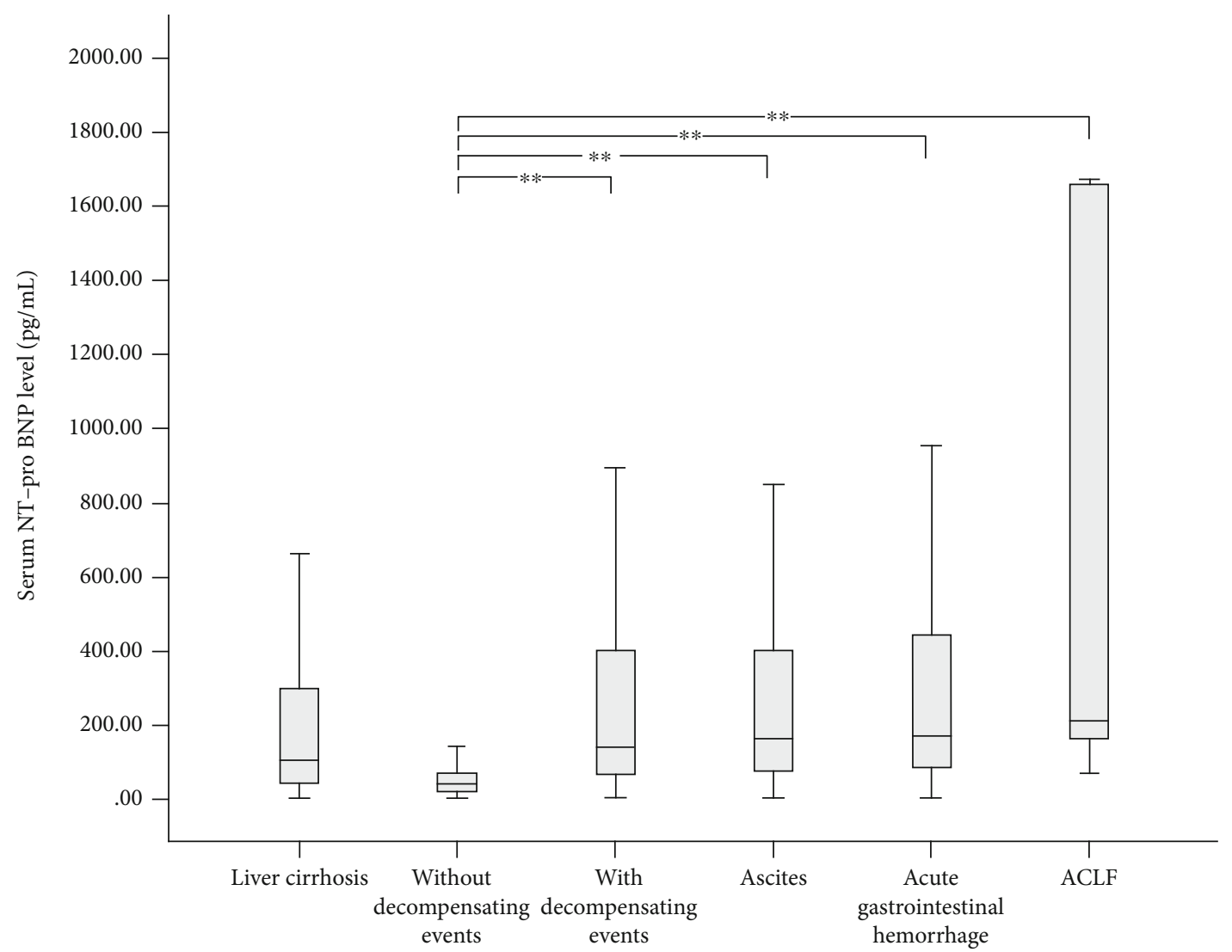

(a)

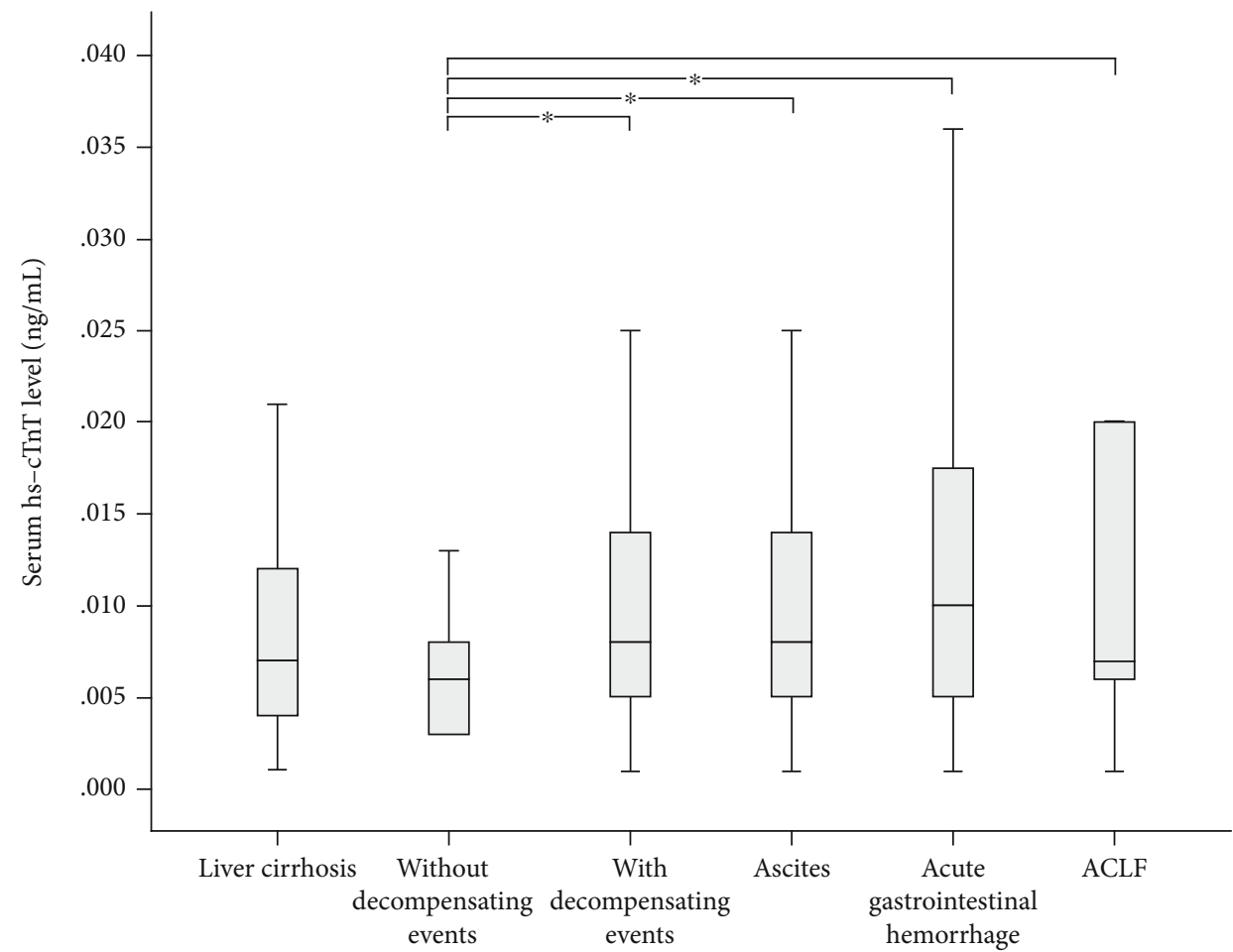

(b)

Figure 2: Continued. 


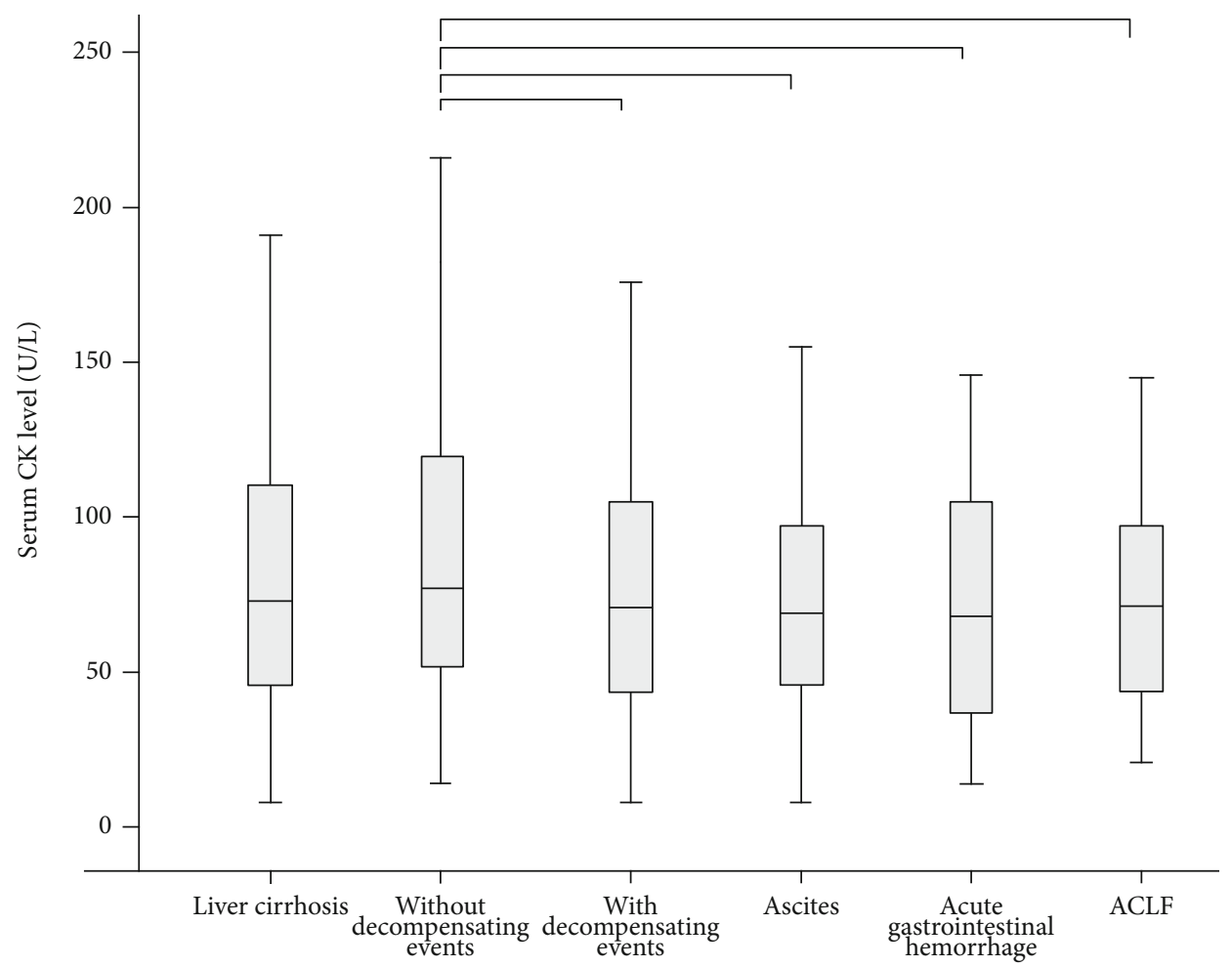

(c)

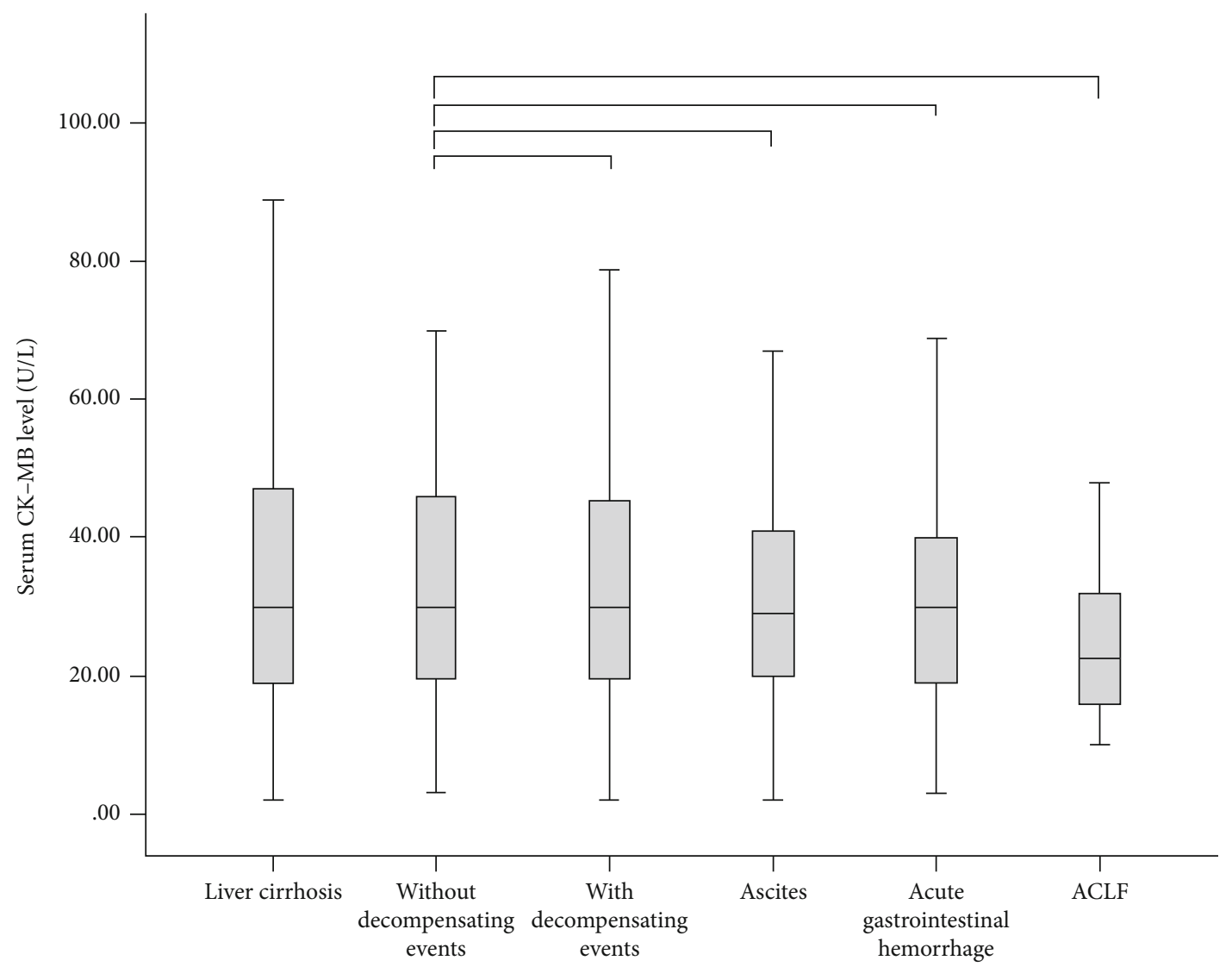

(d)

FIGURE 2: Continued. 


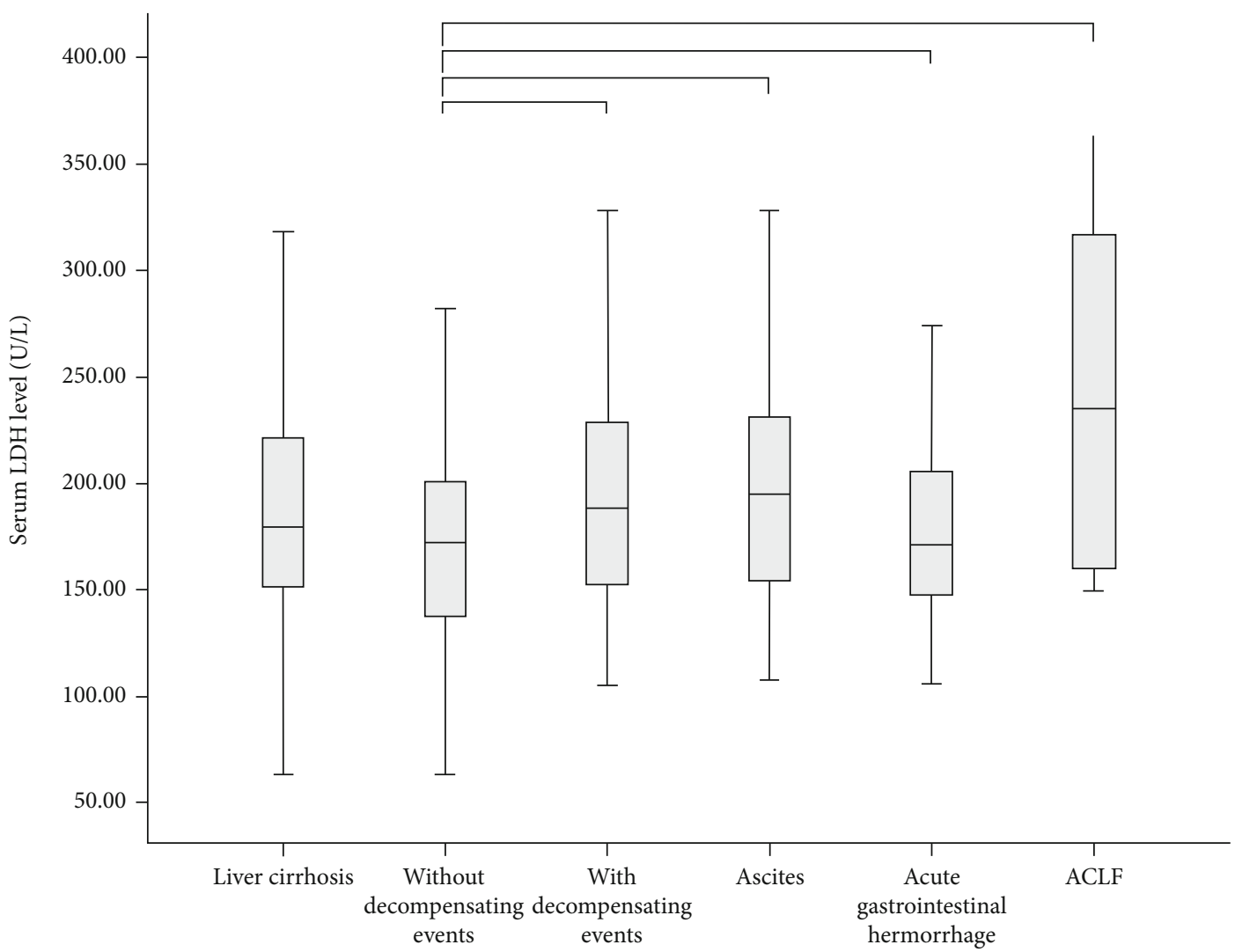

(e)

FIgURE 2: Box plots showing the concentrations of serum NT-pro BNP (a), hs-cTnT (b), CK (c), CK-MB (d), and LDH (e) in general cirrhotic patients, cirrhotic patients with and without decompensating events, cirrhotic patients with ascites, cirrhotic patients with acute gastrointestinal hemorrhage, and cirrhotic patients with ACLF. Notes: ${ }^{* *} P<0.001$ and ${ }^{*} P<0.05$.

CK-MB levels did not significantly correlate with overall acute decompensating events, ascites, acute gastrointestinal hemorrhage, or ACLF; the LDH level significantly correlated with ascites, acute gastrointestinal hemorrhage, and ACLF, but not overall acute decompensating events (Supplementary Table 6).

\section{Discussion}

In this retrospective observational study, we rigorously screened the participants by excluding the confounding factors, which makes our statistical results more reliable. Additionally, we included a relatively large number of cirrhotic patients, which makes our conclusions more representative. The major findings are as follows: (i) the NT-pro BNP level was significantly higher in decompensated cirrhosis. (ii) The NT-pro BNP level also significantly correlated with Child-Pugh and MELD scores in cirrhosis with acute decompensation, but not in those without decompensation. (iii) The hs-cTnT level was elevated in cirrhosis with acute decompensation but was unrelated to the liver disease severity. (iv) The LDH level significantly correlated with ChildPugh and MELD scores in cirrhosis, but was unrelated to decompensating events. (v) CK and CK-MB levels were neither significantly increased in cirrhosis with decompensation nor correlated with Child-Pugh and MELD scores.
4.1. NT-pro BNP. NT-pro BNP, a prohormone of BNP, is secreted into the systemic circulation by cardiac ventricles in response to myocardial hypertrophy and is involved in the regulation of cardiac volume homeostasis [27-29]. Thus, the NT-pro BNP level is often considered as an effective and useful marker for screening of early stages of cardiac dysfunction [30]. As we know, cirrhotic cardiomyopathy is a chronic cardiac systolic and diastolic dysfunction in cirrhotic patients in the absence of prior heart disease $[31,32]$. There is no obvious abnormal change of cardiac function in the resting state; besides, a decreased afterload in cirrhosis often results in normal or even increased left ventricular ejection fraction [31]. Thus, noninvasive cardiac biomarkers are potentially useful to reflect the slight change of pressure state of enddiastolic wall stress and intracardiac filling pressures.

The serum NT-pro BNP level is significantly higher in patients with liver cirrhosis $[7,9,10,12,33]$, probably because it is often associated with hyperdynamic circulation, such as increased heart rate and cardiac output, thereby impairing cardiac contractility [34-36]. Our study for the first time found that the serum NT-pro BNP level was significantly higher in cirrhotic patients who suffer an acute decompensation, such as ascites, gastrointestinal hemorrhage, and ACLF, when the values were compared to those without decompensation. Interestingly, we also found that the NT-pro BNP level significantly correlated with Child- 


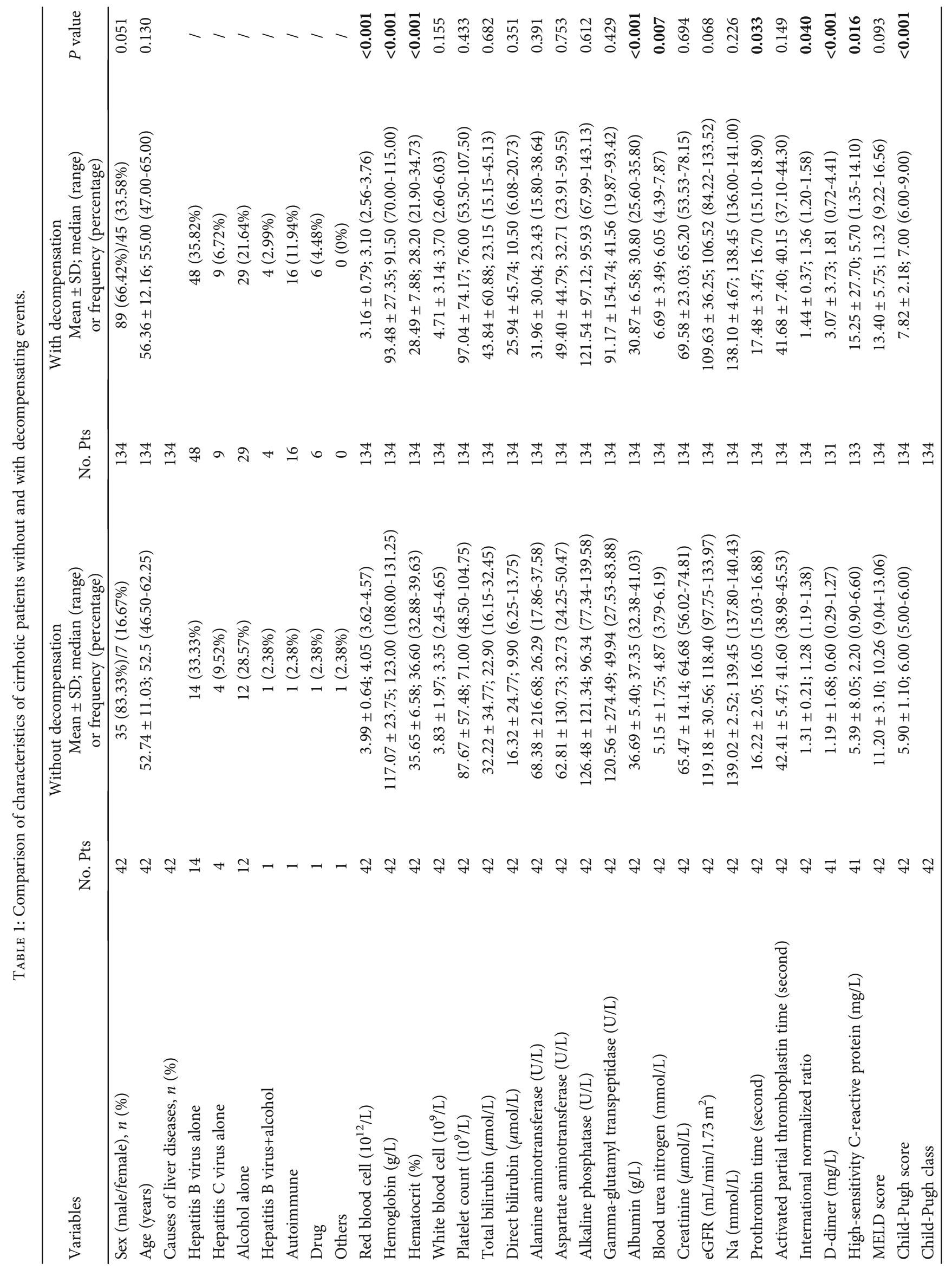




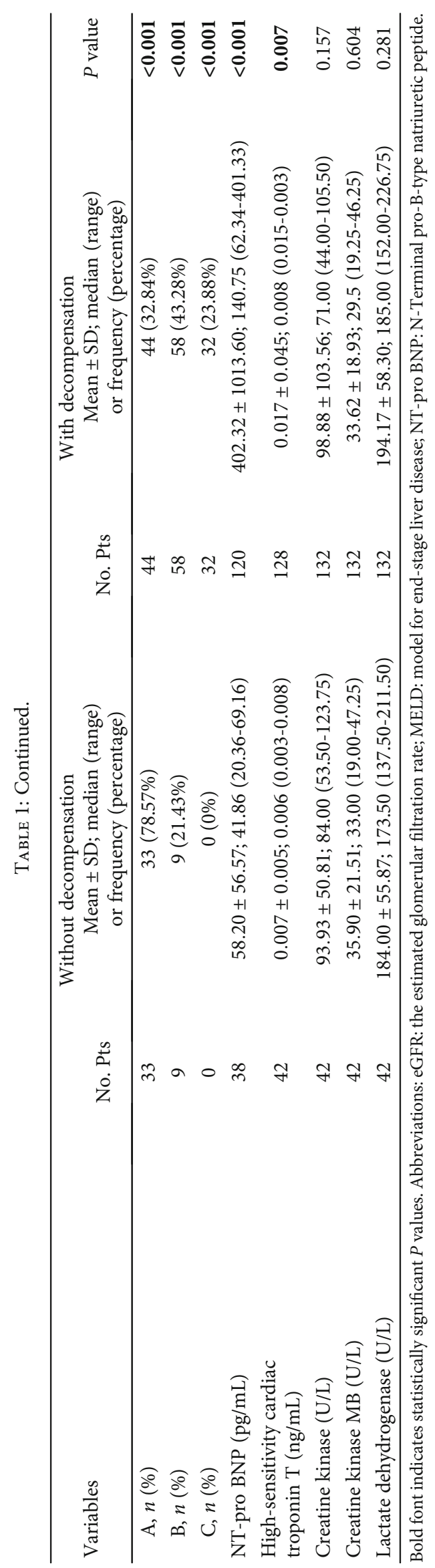




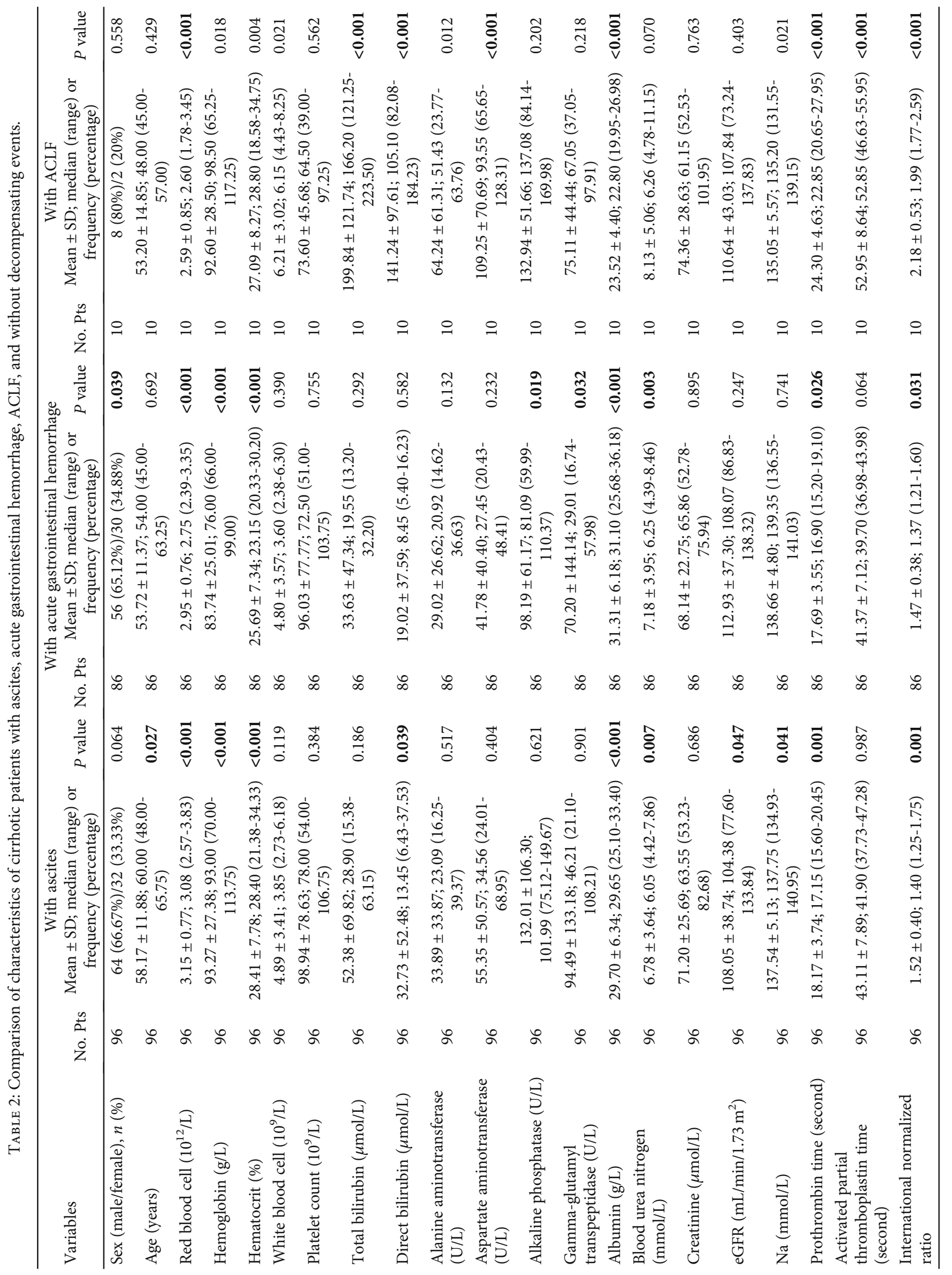




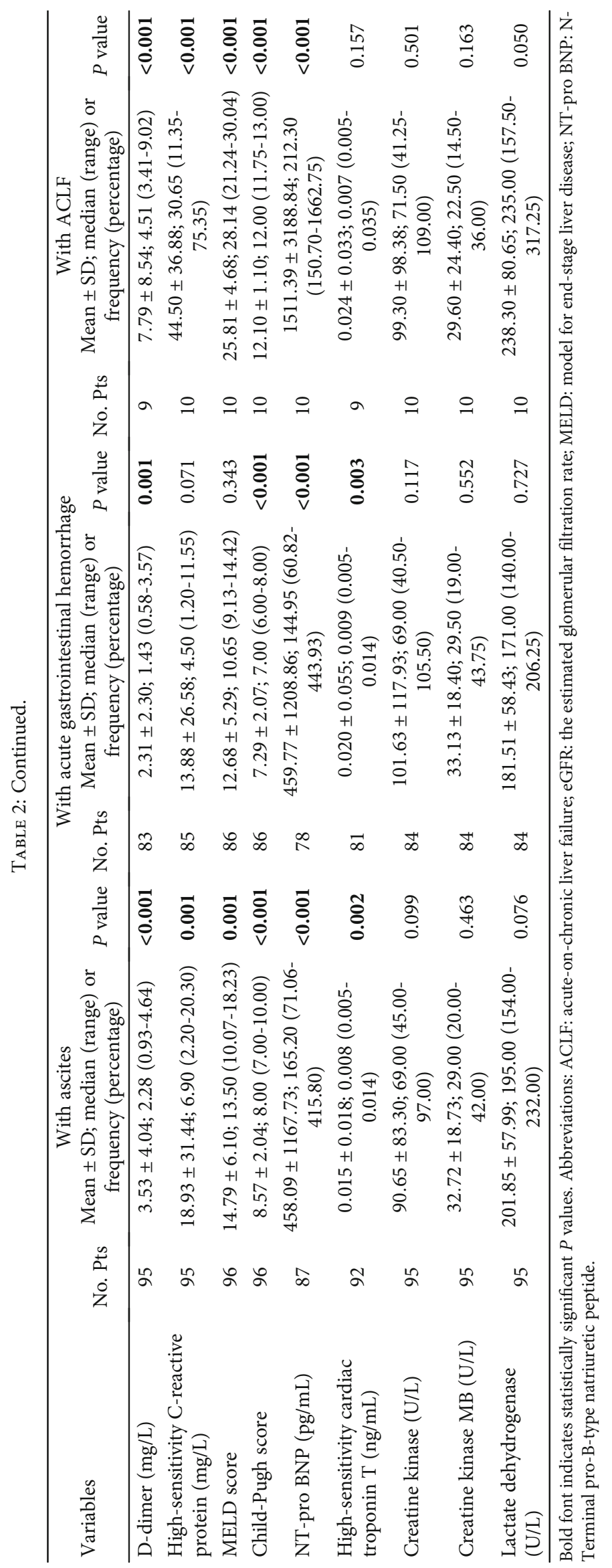


TABLE 3: Partial correlation analysis of the NT-pro BNP level in cirrhosis.

\begin{tabular}{|c|c|c|c|c|c|c|c|c|c|}
\hline \multirow{2}{*}{ Variables } & \multicolumn{3}{|c|}{ All liver cirrhosis } & \multicolumn{3}{|c|}{$\begin{array}{l}\text { Liver cirrhosis without } \\
\text { decompensation }\end{array}$} & \multicolumn{3}{|c|}{$\begin{array}{l}\text { Liver cirrhosis with } \\
\text { decompensation }\end{array}$} \\
\hline & $\begin{array}{l}\text { No. } \\
\text { Pts }\end{array}$ & $P$ value & $\begin{array}{l}\text { Correlation } \\
\text { coefficient }\end{array}$ & $\begin{array}{l}\text { No. } \\
\text { Pts }\end{array}$ & $P$ value & $\begin{array}{l}\text { Correlation } \\
\text { coefficient }\end{array}$ & $\begin{array}{l}\text { No. } \\
\text { Pts }\end{array}$ & $P$ value & $\begin{array}{l}\text { Correlation } \\
\text { coefficient }\end{array}$ \\
\hline Age (years) & l & Controlling & l & l & Controlling & l & l & Controlling & l \\
\hline Sex (male/female), $n(\%)$ & l & Controlling & l & l & Controlling & l & l & Controlling & l \\
\hline Red blood cell $\left(10^{12} / \mathrm{L}\right)$ & 154 & $<0.001$ & -0.322 & 34 & 0.023 & -0.379 & 116 & 0.001 & -0.313 \\
\hline Hemoglobin $(\mathrm{g} / \mathrm{L})$ & 154 & 0.004 & -0.229 & 34 & 0.001 & -0.540 & 116 & 0.025 & -0.207 \\
\hline Hematocrit (\%) & 154 & 0.001 & -0.254 & 34 & 0.001 & -0.523 & 116 & 0.011 & -0.234 \\
\hline White blood cell $\left(10^{9} / \mathrm{L}\right)$ & 154 & 0.027 & 0.177 & 34 & 0.093 & -0.284 & 116 & 0.058 & 0.175 \\
\hline Platelet count $\left(10^{9} / \mathrm{L}\right)$ & 154 & 0.894 & -0.011 & 34 & 0.201 & -0.218 & 116 & 0.842 & -0.018 \\
\hline Total bilirubin $(\mu \mathrm{mol} / \mathrm{L})$ & 154 & 0.027 & 0.178 & 34 & 0.755 & -0.054 & 116 & 0.054 & 0.178 \\
\hline Direct bilirubin $(\mu \mathrm{mol} / \mathrm{L})$ & 154 & 0.063 & 0.149 & 34 & 0.661 & -0.076 & 116 & 0.113 & 0.146 \\
\hline $\begin{array}{l}\text { Alanine aminotransferase } \\
(\mathrm{U} / \mathrm{L})\end{array}$ & 154 & 0.715 & -0.029 & 34 & 0.534 & -0.107 & 116 & 0.609 & -0.048 \\
\hline $\begin{array}{l}\text { Aspartate aminotransferase } \\
(\mathrm{U} / \mathrm{L})\end{array}$ & 154 & 0.694 & -0.032 & 34 & 0.493 & -0.118 & 116 & 0.687 & -0.037 \\
\hline Alkaline phosphatase (U/L) & 154 & 0.534 & -0.050 & 34 & 0.071 & -0.304 & 116 & 0.623 & -0.046 \\
\hline $\begin{array}{l}\text { Gamma-glutamyl } \\
\text { transpeptidase (U/L) }\end{array}$ & 154 & 0.983 & -0.002 & 34 & 0.206 & -0.216 & 116 & 0.794 & 0.024 \\
\hline Albumin $(\mathrm{g} / \mathrm{L})$ & 154 & 0.006 & -0.219 & 34 & 0.263 & -0.192 & 116 & 0.042 & -0.188 \\
\hline Blood urea nitrogen $(\mathrm{mmol} / \mathrm{L})$ & 154 & 0.022 & 0.183 & 34 & 0.099 & 0.279 & 116 & 0.074 & 0.165 \\
\hline Creatinine $(\mu \mathrm{mol} / \mathrm{L})$ & 154 & 0.692 & -0.032 & 34 & 0.755 & -0.054 & 116 & 0.547 & -0.056 \\
\hline $\mathrm{eGFR}\left(\mathrm{mL} / \mathrm{min} / 1.73 \mathrm{~m}^{2}\right)$ & 154 & 0.073 & 0.144 & 34 & 0.823 & 0.039 & 116 & 0.058 & 0.175 \\
\hline Sodium $(\mathrm{mmol} / \mathrm{L})$ & 154 & 0.039 & -0.165 & 34 & 0.586 & 0.094 & 116 & 0.082 & -0.161 \\
\hline Prothrombin time (second) & 154 & $<0.001$ & 0.416 & 34 & 0.480 & 0.122 & 116 & $<0.001$ & 0.419 \\
\hline $\begin{array}{l}\text { Activated partial } \\
\text { thromboplastin time (second) }\end{array}$ & 154 & 0.023 & 0.182 & 34 & 0.406 & 0.143 & 116 & 0.030 & 0.200 \\
\hline International normalized ratio & 154 & $<0.001$ & 0.436 & 34 & 0.380 & 0.151 & 116 & $<0.001$ & 0.439 \\
\hline $\mathrm{D}$-dimer (mg/L) & 153 & 0.003 & 0.241 & 34 & 0.125 & 0.260 & 115 & 0.040 & 0.190 \\
\hline $\begin{array}{l}\text { High-sensitivity C-reactive } \\
\text { protein }(\mathrm{mg} / \mathrm{L})\end{array}$ & 153 & $<0.001$ & 0.285 & 33 & 0.576 & 0.098 & 116 & 0.003 & 0.270 \\
\hline MELD score & 154 & $<0.001$ & 0.302 & 34 & 0.701 & 0.066 & 116 & 0.001 & 0.296 \\
\hline Child-Pugh score & 154 & $<0.001$ & 0.346 & 34 & 0.279 & 0.185 & 116 & $<0.001$ & 0.325 \\
\hline $\begin{array}{l}\text { High-sensitivity cardiac } \\
\text { troponin } \mathrm{T}(\mathrm{ng} / \mathrm{mL})\end{array}$ & 151 & 0.004 & 0.229 & 34 & 0.062 & -0.315 & 113 & 0.026 & 0.208 \\
\hline Creatine kinase (U/L) & 154 & 0.653 & -0.036 & 34 & 0.567 & 0.099 & 116 & 0.588 & -0.050 \\
\hline Creatine kinase $\mathrm{MB}(\mathrm{U} / \mathrm{L})$ & 154 & 0.209 & -0.101 & 34 & 0.744 & -0.056 & 116 & 0.217 & -0.115 \\
\hline Lactate dehydrogenase (U/L) & 154 & 0.622 & -0.040 & 34 & 0.985 & -0.003 & 116 & 0.586 & -0.051 \\
\hline
\end{tabular}

Bold font indicates statistically significant $P$ values. Abbreviations: NT-pro BNP: N-Terminal pro-B-type natriuretic peptide; eGFR: the estimated glomerular filtration rate; MELD: model for end-stage liver disease.

Pugh and MELD scores in cirrhotic patients with acute decompensating events, but not in those without decompensation, which would suggest that NT-pro BNP can reflect the insidious change of cardiac dysfunction in advanced cirrhosis with cardiac dysfunction.

In addition, BNP is a natriuretic hormone released from myocardial cells in response to volume expansion, enddiastolic wall stress, and possibly increased intracardiac filling pressures $[8,37]$. Hypertrophy of the left ventricle, left-atrial dilatation, and increased end-diastolic and endsystolic left-ventricular volume are frequently observed in liver cirrhosis $[1,32,38,39]$, which are potentially the main causes for an increase of NT-pro BNP.

4.2. hs-cTnT. hs-cTnT, a protein complex regulating the contraction of striated muscle, is released when myocardial ischemia induces nonreversible injury of myocardial tissue [40]. hs-cTnT is a specific and sensitive biomarker of myocardial damage and is being widely used for clinical screening in patients with suspected acute myocardial infarction $[41,42]$, but not for evaluating the change of myocardial contractility. The hs-cTnT level can be also elevated in some 
TABLE 4: Multivariate linear regression analysis of factors associated with the NT-pro BNP level.

\begin{tabular}{lccc}
\hline \multirow{2}{*}{ Factors } & No. & \multicolumn{2}{c}{ Age-adjusted } \\
& Pts & $B$-coefficient $(S E)$ & $P$ value \\
\hline Age & 158 & $0.302(0.008)$ & $<\mathbf{0 . 0 0 1}$ \\
Gender & 158 & $0.106(0.214)$ & 0.137 \\
Acute decompensating events & 158 & $0.432(0.229)$ & $<\mathbf{0 . 0 0 1}$ \\
Ascites & 158 & $0.175(0.195)$ & $\mathbf{0 . 0 1 4}$ \\
Acute gastrointestinal & 158 & $0.309(0.183)$ & $<\mathbf{0 . 0 0 1}$ \\
hemorrhage & 158 & $0.218(0.384)$ & $<\mathbf{0 . 0 0 1}$ \\
ACLF &
\end{tabular}

Bold font indicates statistically significant $P$ values. Serum NT-pro BNP concentrations were $\log _{10}$-transformed in order to normalize their distribution. Abbreviations: NT-pro BNP: N-Terminal pro-B-type natriuretic peptide; SE: standard error; ACLF: acute-on-chronic liver failure.

cardiac and noncardiac conditions, such as severe renal insufficiency [43-46], tachycardia, pericarditis, vigorous exercise [47], and atrial fibrillation [48-50]. The present study has rigorously excluded these conditions. The hscTnT level seems to be related to the severity and survival of cirrhotic patients $[12,14]$. Our results also showed that the hs-cTnT level was significantly higher in decompensated cirrhotic patients than those without decompensation. This association was mainly attributed to the effect of acute gastrointestinal hemorrhage, but not to ascites or ACLF (Supplementary Table 5). A possible explanation for this finding could be that acute gastrointestinal bleeding in cirrhotic patients may lead to hypovolemic hypotension, which is a significant risk factor for myocardial damage [51-53], thereby increasing the levels of myocardial damage biomarkers [54]. The pathophysiological link of the association remains unexplained, and it needs further research to clarify its mechanism.

4.3. $C K$ and $C K-M B$. We did not find any significant difference in $\mathrm{CK}$ and $\mathrm{CK}-\mathrm{MB}$ levels, comparing compensated and decompensated cirrhotic patients. Moreover, there was no correlation of CK and CK-MB levels with Child-Pugh and MELD scores in cirrhosis. These analyses were performed in the groups with and without decompensating events. Traditionally, CK-MB is helpful for estimating the infarct size in acute myocardial infarction and is highly specific to heart tissue $[55,56]$ while $\mathrm{CK}$ is used for assessing myocardial damage in acute myocardial infarction [57]. None of them is a good indicator of cardiac volume overload. Our study suggested that CK and CK-MB levels did not correlate with the severity of cirrhosis.

4.4. $\mathrm{LDH}$. $\mathrm{LDH}$, a cytoplasmic enzyme, exists in a wide range of tissues and is elevated when cells are damaged. $\mathrm{LDH}$ is not specific for the diagnosis of a disease. There are five types of serum LDH isoenzymes. Among them, LDH1 is mainly derived from the heart and LDH5 from the liver [58]. However, LDH5 have lower specificity and sensitivity than ALT for diagnosing and evaluating liver diseases [59]. LDH significantly correlated with Child-Pugh and MELD scores in cirrhotic patients. However, there was no significant difference in LDH levels between cirrhotic patients with and without decompensation. These results indicate that LDH might not be sensitive to early cardiac dysfunction caused by cirrhosis.

4.5. Limitations. First, the number of patients with ACLF was small in our cohort and the relationship between serum cardiac markers and ACLF needs further clarification. Second, a reasonable and convenient approach for quantifying blood loss volume during acute gastrointestinal hemorrhage and volume of ascites was unavailable. Third, healthy controls may make the results more comprehensive. Further studies should further consider the effects of the severity of such decompensating events on the long-term prognosis.

\section{Conclusion}

An elevated NT-pro BNP level might be useful to identify the cardiac volume overload caused by acute decompensating events in advanced cirrhosis. Additionally, the hs-cTnT level was elevated in cirrhosis with acute decompensating events.

\section{Data Availability}

The data used to support the findings of this study are available from the corresponding author upon reasonable request.

\section{Disclosure}

The abstract was published in the Asian Pacific Association for the Study of the Liver (APASL) 2020 Conference as a poster presentation. Please see the following link: https:// link.springer.com/content/pdf/10.1007/s12072-020-10030-4 .pdf.

\section{Conflicts of Interest}

The authors declare that they have no conflicts of interest.

\section{Authors' Contributions}

Miaomiao Li reviewed the literature, wrote the study protocol, collected the data, performed the statistical analyses, and drafted the manuscript; Zeqi Guo, Dan Zhang, Xiangbo $\mathrm{Xu}$, Fernando Gomes Romeiro, Andrea Mancuso, Jingqiao Zhang, Ruirui Feng, Xinmiao Zhou, and Cen Hong collected the data, checked the data, and gave critical comments; Xingshun Qi conceived the study, reviewed the literature, wrote the study protocol, treated the patients, checked the data, gave critical comments, and revised the manuscript. All authors have made an intellectual contribution to the manuscript and approved the submission. Miaomiao Li, Zeqi Guo, Dan Zhang, and Xiangbo Xu are co-first authors.

\section{Acknowledgments}

We would like to appreciate our study team for setting up and updating the prospective database, including Wenchun Bao, Feifei Hou, Zeqi Guo, Jingqiao Zhang, Xinmiao Zhou, Miaomiao Li, Ruirui Feng, Cen Hong, and Shixue $\mathrm{Xu}$, of whom all had worked for our study group of establishing 
and updating this database, which prospectively recorded the patients treated by Dr. Xingshun Qi. The study was partially supported by the Science and Technology Project Foundation of Shenyang (19-112-4-005).

\section{Supplementary Materials}

Supplementary Table 1: a table showing partial correlation analysis of the hs-cTnT level in cirrhotic patients, cirrhotic patients with and without decompensation using $P$ value, correlation coefficient parameter. Supplementary Table 2: a table showing partial correlation analysis of the CK level in cirrhotic patients using $P$ value, correlation coefficient parameter. Supplementary Table 3: a table showing partial correlation analysis of the CK-MB level in cirrhotic patients using $P$ value, correlation coefficient parameter. Supplementary Table 4: a table showing partial correlation analysis of the LDH level in cirrhotic patients using $P$ value, correlation coefficient parameter. Supplementary Table 5: a table showing multivariate linear regression analysis of factors, such as age, gender, acute decompensation, ascites, acute gastrointestinal hemorrhage, and ACLF, associated with the hs-cTnT level in cirrhotic patients using $P$ value, $B$-coefficient parameter. Supplementary Table 6: a table showing multivariate linear regression analysis of factors, such as age, gender, acute decompensation, ascites, acute gastrointestinal hemorrhage, and ACLF, associated with CK, CK-MB, and LDH levels in cirrhotic patients using $P$ value, $B$-coefficient parameter. (Supplementary Materials)

\section{References}

[1] A. Milani, R. Zaccaria, G. Bombardieri, A. Gasbarrini, and P. Pola, "Cirrhotic cardiomyopathy," Digestive and Liver Disease, vol. 39, no. 6, pp. 507-515, 2007.

[2] J. H. Henriksen, S. Møller, H. Ring-Larsen, and N. J. Christensen, "The sympathetic nervous system in liver disease," Journal of Hepatology, vol. 29, no. 2, pp. 328-341, 1998.

[3] S. Moller, F. Bendtsen, and J. H. Henriksen, "Determinants of the renin-angiotensin-aldosterone system in cirrhosis with special emphasis on the central blood volume," Scandinavian Journal of Gastroenterology, vol. 41, no. 4, pp. 451-458, 2009.

[4] S. Moller and J. H. Henriksen, "Cirrhotic cardiomyopathy," Journal of Hepatology, vol. 53, no. 1, pp. 179-190, 2010.

[5] T. Timoh, M. A. Protano, G. Wagman, M. Bloom, and T. J. Vittorio, "A perspective on cirrhotic cardiomyopathy," Transplantation Proceedings, vol. 43, no. 5, pp. 1649-1653, 2011.

[6] M. K. York, D. K. Gupta, C. F. Reynolds et al., "B-type natriuretic peptide levels and mortality in patients with and without heart failure," Journal of the American College of Cardiology, vol. 71, no. 19, pp. 2079-2088, 2018.

[7] L. Y. Shi, R. Jin, C. J. Lin et al., "B-type natriuretic peptide and cirrhosis progression," Genetics and Molecular Research, vol. 14, no. 2, pp. 5188-5196, 2015.

[8] C. Mueller, K. McDonald, R. A. de Boer et al., "Heart Failure Association of the European Society of Cardiology practical guidance on the use of natriuretic peptide concentrations," European Journal of Heart Failure, vol. 21, no. 6, pp. 715731, 2019.
[9] J. H. Henriksen, J. P. Gøtze, S. Fuglsang, E. Christensen, F. Bendtsen, and S. Møller, "Increased circulating pro-brain natriuretic peptide (proBNP) and brain natriuretic peptide (BNP) in patients with cirrhosis: relation to cardiovascular dysfunction and severity of disease," Gut, vol. 52, no. 10, pp. 1511-1517, 2003.

[10] R. Yildiz, B. Yildirim, M. Karincaoglu, M. Harputluoglu, and F. Hilmioglu, "Brain natriuretic peptide and severity of disease in non-alcoholic cirrhotic patients," Journal of Gastroenterology and Hepatology, vol. 20, no. 7, pp. 1115-1120, 2005.

[11] V. Bernal, I. Pascual, P. Esquivias et al., "Cardiac hemodynamic profiles and pro-B-type natriuretic peptide in cirrhotic patients undergoing liver transplantation," Transplantation Proceedings, vol. 41, no. 3, pp. 985-986, 2009.

[12] J. Zhao, S. Li, L. Ren, X. Guo, and X. Qi, "Pro-brain natriuretic peptide and troponin T-hypersensitivity levels correlate with the severity of liver dysfunction in liver cirrhosis," The American Journal of the Medical Sciences, vol. 354, no. 2, pp. 131139, 2017.

[13] Y. Peng, X. Qi, J. Dai, H. Li, and X. Guo, "Child-Pugh versus MELD score for predicting the in-hospital mortality of acute upper gastrointestinal bleeding in liver cirrhosis," International Journal of Clinical and Experimental Medicine, vol. 8, no. 1, pp. 751-757, 2015.

[14] S. Wiese, C. Mortensen, J. P. Gøtze et al., "Cardiac and proinflammatory markers predict prognosis in cirrhosis," Liver International, vol. 34, no. 6, pp. e19-e30, 2014.

[15] R. N. H. Pugh, I. M. Murray-Lyon, J. L. Dawson, M. C. Pietroni, and R. Williams, "Transection of the oesophagus for bleeding oesophageal varices," The British Journal of Surgery, vol. 60, no. 8, pp. 646-649, 1973.

[16] https://optn.transplant.hrsa.gov/news/meld-serum-sodiumpolicy-changes/.

[17] K. P. Moore, F. Wong, P. Gines et al., "The management of ascites in cirrhosis: report on the consensus conference of the International Ascites Club," Hepatology, vol. 38, no. 1, pp. 258-266, 2003.

[18] S. K. Sarin, A. Kumar, J. A. Almeida et al., "Acute-on-chronic liver failure: consensus recommendations of the Asian Pacific Association for the Study of the Liver (APASL) 2014," Нераtology International, vol. 8, no. 4, pp. 453-471, 2014.

[19] S. K. Sarin, A. Kumar, J. A. Almeida et al., "Acute-on-chronic liver failure: consensus recommendations of the Asian Pacific Association for the Study of the Liver (APASL)," Hepatology International, vol. 3, no. 1, pp. 269-282, 2009.

[20] K. Sooklim, S. Srimahachota, S. Boonyaratavej et al., "Renal dysfunction as an independent predictor of total mortality after acute coronary syndrome: the Thai ACS registry," Journal of the Medical Association of Thailand, vol. 90, Suppl 1, pp. 32-40, 2007.

[21] A. S. Levey, J. Coresh, T. Greene et al., "Using standardized serum creatinine values in the modification of diet in renal disease study equation for estimating glomerular filtration rate," Annals of Internal Medicine, vol. 145, no. 4, pp. 247-254, 2006.

[22] I. Raymond, B. A. Groenning, P. R. Hildebrandt et al., "The influence of age, sex and other variables on the plasma level of $\mathrm{N}$-terminal pro brain natriuretic peptide in a large sample of the general population," Heart, vol. 89, no. 7, pp. 745-751, 2003.

[23] I. Loke, I. B. Squire, J. E. Davies, and L. L. Ng, "Reference ranges for natriuretic peptides for diagnostic use are 
dependent on age, gender and heart rate," European Journal of Heart Failure, vol. 5, no. 5, pp. 599-606, 2014.

[24] Y. Alibay, C. Schmitt, A. Beauchet et al., "Non-radioimmunometric NT-ProBNP and BNP assays: impact of diluent, age, gender, BMI," Annales de Biologie Clinique, vol. 63, no. 1, pp. 43-49, 2005.

[25] F. S. Apple and P. O. Collinson, "Analytical characteristics of high-sensitivity cardiac troponin assays," Clinical Chemistry, vol. 58, no. 1, pp. 54-61, 2012.

[26] A. S. Shah, M. Griffiths, K. K. Lee et al., "High sensitivity cardiac troponin and the under-diagnosis of myocardial infarction in women: prospective cohort study," Bmj, vol. 350, no. jan21 4, p. g7873, 2015.

[27] J. A. de Lemos, D. K. McGuire, and M. H. Drazner, "B-type natriuretic peptide in cardiovascular disease," Lancet, vol. 362, no. 9380, pp. 316-322, 2003.

[28] M. Weber and C. Hamm, "Role of B-type natriuretic peptide (BNP) and NT-proBNP in clinical routine," Heart, vol. 92, no. 6, pp. 843-849, 2006.

[29] M. R. Cowie, P. Jourdain, A. Maisel et al., "Clinical applications of B-type natriuretic peptide (BNP) testing," European Heart Journal, vol. 24, no. 19, pp. 1710-1718, 2003.

[30] M. D. TA, S. D. Robb, D. R. Murdoch et al., "Biochemical detection of left-ventricular systolic dysfunction," Lancet, vol. 351, no. 9095, pp. 9-13, 1998.

[31] M. Izzy, V. W. LB, G. Lin et al., "Redefining cirrhotic cardiomyopathy for the modern era," Hepatology, vol. 71, no. 1, pp. 334-345, 2020.

[32] S. Møller and J. H. Henriksen, "Cardiovascular complications of cirrhosis," Gut, vol. 57, no. 2, pp. 268-278, 2008.

[33] A. Licata, S. Corrao, S. Petta et al., "NT pro BNP plasma level and atrial volume are linked to the severity of liver cirrhosis," PLoS One, vol. 8, no. 8, article e68364, 2013.

[34] J. E. Naschitz, G. Slobodin, R. J. Lewis, E. Zuckerman, and D. Yeshurun, "Heart diseases affecting the liver and liver diseases affecting the heart," American Heart Journal, vol. 140, no. 1, pp. 111-120, 2000.

[35] M. Pozzi, S. Carugo, G. Boari et al., "Evidence of functional and structural cardiac abnormalities in cirrhotic patients with and without ascites," Hepatology, vol. 26, no. 5, pp. 1131-1137, 1997.

[36] A. Vannucci, R. Rathor, N. Vachharajani, W. Chapman, and I. Kangrga, "Atrial fibrillation in patients undergoing liver transplantation-a single-center experience," Transplantation Proceedings, vol. 46, no. 5, pp. 1432-1437, 2014.

[37] T. Kawamura, M. Yasuda, M. Okune et al., "Increased left ventricular trabeculation is associated with increased B-type natriuretic peptide levels and impaired outcomes in nonischemic cardiomyopathy," The Canadian Journal of Cardiology, vol. 36, no. 4, pp. 518-526, 2020.

[38] M. H. Wehmeyer, A. J. Heuer, D. Benten et al., "High Rate of Cardiac Abnormalities in a Postmortem Analysis of Patients Suffering From Liver Cirrhosis," Journal of Clinical Gastroenterology, vol. 49, no. 10, pp. 866-872, 2015.

[39] O. M. Silvestre, F. Bacal, D. . S. Ramos et al., "Impact of the severity of end-stage liver disease in cardiac structure and function," Annals of Hepatology, vol. 12, no. 1, pp. 85-91, 2013.

[40] P. A. Kavsak, J. E. Andruchow, A. D. McRae, and A. Worster, "Profile of Roche's Elecsys Troponin T Gen 5 STAT blood test (a high-sensitivity cardiac troponin assay) for diagnosing myo- cardial infarction in the emergency department," Expert Review of Molecular Diagnostics, vol. 18, no. 6, pp. 481-489, 2018.

[41] B. Lindahl, P. Venge, and L. Wallentin, "The FRISC experience with troponin $\mathrm{T}$. Use as decision tool and comparison with other prognostic markers," European heart journal, vol. 19, pp. N51-N58, 1998.

[42] B. Luu, D. M. Leistner, E. Herrmann et al., "Minute myocardial injury as measured by high-sensitive troponin T serum levels predicts the response to intracoronary infusion of bone marrow-derived mononuclear cells in patients with stable chronic post-infarction heart failure: insights from the TOPCARE-CHD registry," Circulation Research, vol. 120, no. 12, pp. 1938-1946, 2017.

[43] V. Fridén, K. Starnberg, A. Muslimovic et al., "Clearance of cardiac troponin T with and without kidney function," Clinical Biochemistry, vol. 50, no. 9, pp. 468-474, 2017.

[44] B. J. Freda, W. H. W. Tang, F. van Lente, W. F. Peacock, and G. S. Francis, "Cardiac troponins in renal insufficiency: review and clinical implications," Journal of the American College of Cardiology, vol. 40, no. 12, pp. 2065-2071, 2002.

[45] R. Robitaille and J. M. Lafrance, "Altered laboratory findings associated with end-stage renal disease," Seminars in Dialysis, 2006.

[46] F. S. Apple, M. M. Murakami, L. A. Pearce, and C. A. Herzog, "Predictivevalue of troponin I and T for death in End-Stage Disease," Circulation, vol. 106, no. 23, pp. 2941-2945, 2002.

[47] T. K. Bakshi, M. K. Choo, C. C. Edwards, A. G. Scott, H. H. Hart, and G. P. Armstrong, "Causes of elevated troponin I with a normal coronary angiogram," Internal Medicine Journal, vol. 32, no. 11, pp. 520-525, 2010.

[48] Z. Hijazi, L. Wallentin, A. Siegbahn et al., "High-sensitivity troponin $\mathrm{T}$ and risk stratification in patients with atrial fibrillation during treatment with apixaban or warfarin," Journal of the American College of Cardiology, vol. 63, no. 1, pp. 5261, 2014.

[49] Z. Hijazi, J. Oldgren, U. Andersson et al., "Cardiac Biomarkers Are Associated With an Increased Risk of Stroke and Death in Patients With Atrial Fibrillation," Circulation, vol. 125, no. 13, pp. 1605-1616, 2012.

[50] Z. Hijazi, A. Siegbahn, U. Andersson et al., "High-sensitivity troponin I for risk assessment in patients with atrial Fibrillation," Circulation, vol. 129, no. 6, pp. 625-634, 2014.

[51] D. M. Iser, A. J. Thompson, K. K. Sia, N. D. Yeomans, and R. Y. Chen, "Prospective study of cardiac troponin I release in patients with upper gastrointestinal bleeding," Journal of Gastroenterology and Hepatology, vol. 23, no. 6, pp. 938942, 2008.

[52] M. Cappell and D. Friedel, "Initial management of acute upper gastrointestinal bleeding: from initial evaluation up to gastrointestinal endoscopy," The Medical Clinics of North America, vol. 92, no. 3, pp. 491-509, 2008.

[53] M. Cappell, "A study of the syndrome of simultaneous acute upper gastrointestinal bleeding and myocardial infarction in 36 patients," The American Journal of Gastroenterology, vol. 90, no. 9, pp. 1444-1449, 1995.

[54] S. Arlati, S. Brenna, L. Prencipe et al., "Myocardial necrosis in ICU patients with acute non-cardiac disease: a prospective study," Intensive Care Medicine, vol. 26, no. 1, pp. 31-37, 2000.

[55] J. E. Adams 3rd, D. R. Abendschein, and A. S. Jaffe, "Biochemical markers of myocardial injury. Is $\mathrm{MB}$ creatine kinase the 
choice for the 1990s?," Circulation, vol. 88, no. 2, pp. 750-763, 1993.

[56] F. S. Apple, H. E. Quist, P. J. Doyle, A. P. Otto, and M. A. M. Murakami, "Plasma 99th percentile reference limits for cardiac troponin and creatine kinase MB mass for use with European Society of Cardiology/American College of Cardiology consensus recommendations," Clinical Chemistry, vol. 49, no. 8 , pp. 1331-1336, 2003.

[57] G. V. Heller, A. S. Blaustein, and J. Y. Wei, "Implications of increased myocardial isoenzyme level in the presence of normal serum creatine kinase activity," The American Journal of Cardiology, vol. 51, no. 1, pp. 24-27, 1983.

[58] M. J. Smit, A. M. Duursma, J. M. Bouma, and M. Gruber, "Receptor-mediated endocytosis of lactate dehydrogenase M4 by liver macrophages: a mechanism for elimination of enzymes from plasma. Evidence for competition by creatine kinase MM, adenylate kinase, malate, and alcohol dehydrogenase," The Journal of Biological Chemistry, vol. 262, no. 27, pp. 13020-13026, 1987.

[59] T. Marshall, J. Williams, and K. M. Williams, "Electrophoresis of serum isoenzymes and proteins following acute myocardial infarction," Journal of Chromatography, vol. 569, no. 1-2, pp. 323-345, 1991. 